\title{
Socio-Technological Characterization of Goat Industry at Tamarugal Province in Atacama Desert
}

\author{
Sergio Diez-de-Medina R. ${ }^{1,2 \star}$, Pamela Cabello ${ }^{1,2}$, Juan Carlos Ríos ${ }^{1,2}$, Pablo Figueroa ${ }^{1}$, Iván Balic ${ }^{1}$, \\ Damien Hardy ${ }^{3}$ and Viviana Vrsalovic ${ }^{1}$
}

\begin{abstract}
The following article displays a study carried over the goat producers in the northern Tamarugal province in Chile, including the analysis of a survey that characterizes the technical capability of the industry mainly constituted by altiplanean natives communities, exposing the needs that the innovation system requires to be improved in order to boost the generation of added value products useful for project sustainability of these communities. As well, sensitization of the main social breakthroughs is made in order to develop an effective technology transfer to the communities to accomplish this aimed sustainability, through innovative use of the resources.
\end{abstract}

Keywords: Goat; sustainability; Tamarugal; innovation; Chile; Atacama

Submitted August 26th 2015 / Approved September 30th 2015

\section{Introduction}

With a territorial extension of $39,350 \mathrm{Km}^{2}$ located within Atacama Desert, the province of Tamarugal in Chile base its economy mostly in the ore extraction of minerals such as copper and lithium, industry which yields the most important income in the country. Nevertheless and facing a sustainable strategy to the local economy, the local government through the innovation fund for competitiveness (FIC) has allowed to Universidad de Los Lagos project the Center for Animal Reproduction (CRAULA) in order to give technical and administrative assistance to the producers of this region. The goat producers of this region belongs mostly to autochthonous Aymará ethnicity and face extreme conditions to breed the livestock, which include the scarcity of precipitations and vegetation. Despite this the Criolla mixed race with marked influence of Saanen and Anglo Nubian have shown a good adaptation to the handicaps exposed by the desert, showing yields between $32-78 \mathrm{Kg}$ in females and $50-90 \mathrm{Kg}$ in males (Figueroa et al., 2013). The milk production measured is 78, 6 $\mathrm{Kg}$ manually extracted in adult females, letting the animals to be freely fed and rationalizing the water for them in the farms, which comes principally from natural wells. The difficulties that the weather add to the production are summed to the geographical isolation that the north of Chile have from centers with economic relevance $(1800 \mathrm{Km}$ away from the capital Santiago), and the lack of established slaughterhouses which is consider a relevant improvement to do in terms of public policies. Due to these handicaps the producers mainly focus the commercialization of their livestock during 2 main festivities in July and December when the floating population of the region grows, and mobile slaughterhouses are established, trading the meat in form of jerky. Milk production is limited by the conditions and is principally used to produce hand-made cheeses in very small quantities.
Facing these challenges is how CRAULA aims to improve the production and potentiate the local industry, allowing accessibility to promising markets and performing technology transfer from the university to the local producers (Figueroa et al., 2013). In one hand the center is installing a laboratory for the diagnosis and assisted breeding including in-vitro fertilization techniques performed by specialized veterinarians and scientists to improve traits such as milk and meat yield (Dubeuf \& Boyazoglu, 2009; Oman et al., 1999). On the other side the assistance in commercial issues is performed by a group of consultants from the university who have as goals to assess the needs of the producers to construct a proper strategy to reach markets that can yield more benefits to them, taking in account opportunities for project a multiple product development from the biomass generated each season (Cannarella \& Piccioni, 2011).

The first two years of the interaction between the University and the local producers allowed identifying the producer's needs, including the urgent animal health assistance and the willing of the local producers to conform commercial community collaboration in order to explode the availability of the renewable source and project the use of resources that are apparently almost completely lost.

The opportunities In long term relies in the recognition of the best individuals adapted to the desert conditions that can be used for the improvement of different races aiming to increase the yield of meat and milk. In middle term the capacitation of local producers and inhabitants of the region for potentiate the treatment and generation of goat derived products including goat cheese, cured leather and wool for shoes, clothes and handcraft, allowing the impulse of a multiple product development (Drejer \& Gudmundsson, 2002). In short term, the direct improvement of the sanitary conditions and the catalysis

1 Universidad de Los Lagos, New business projects unit, Santiago de Chile.

2 Universidad de los Lagos, Center for Animal Reproduction (CRAULA). Iquique, Chile.

3 Institut de lélevage, Paris, France.

*Corresponding author: sergio.diez@ulagos.cl

ISSN: 0718-2724. (http://jotmi.org)

Journal of Technology Management \& Innovation (c) Universidad Alberto Hurtado, Facultad de Economía y Negocios. 
of the inter-association of small producers in a commercial organization, which can be potentiated with identification of associates for national and international projection of these exotic location goat products (Cannarella \& Piccioni, 2011).

\section{Methods}

The method consisted in the design of an extensive survey of 15 items and multiple alternatives regarding the current situation of producers Tamarugal goats, their cattle, and how to produce. The survey was applied to 72 producers in the Province of Tamarugal between July and October 2014. The extracted results were considered relevant for the interpretation of socio-technical-commercial status of local production. All items were considered and sub-items whose answers given were significant to the total respondent universe. Descriptive analysis was performed, since the data tabulation variables were mainly discrete qualitative and quantitative, it was decided to analysis by means of tables of frequent system with valid values. These tables frequently get, percentage, percentage valid and cumulative percentage. The data was plotted in charts, bar graphs and scatter. Where upon time analysis and conclusions of the observed data was included. The survey was analyzed first by question and then in some cases conducted analysis of relationship between variables related to see if there is any relationship between variables. As turn Crosstabs were performed to analyze variables interest. Was included in the analysis, a projection regarding the age evolution of livestock (Predictive analysis) which was performed by linear regression analyzing two milestones surveys and observing how evolved age.

\section{Results}

A total of 72 goat farmers were consulted with the designed survey in the area, which covered 4 towns from the province. Most herders consulted inhabit the town of Pozo Almonte (74.6\%), also
10 herders from Huara were consulted, equivalent to $14.1 \%$ of surveyed universe. A smaller representation was surveyed in Pica and Camiña towns (Figure 1a). The average ages of surveyed herders are between 41-70 years, corresponding to $70.42 \%$ of respondents (Figure 1b). Implying that the producers' population corresponds mainly elderly people, which in a projection to ten years is estimated will continue aging sector. The average family size (Figure 1c) corresponds principally to groups of $2-4$ people (67.7\%). These families depend mainly on the economic income from just one of the family members for subsistence $(44.8 \%)$. These results in addition to the economic contribution of livestock to the total family income, indicates the high relevance of the goat production for the herders and their families in the area. A considerable $12.7 \%$ of the population depend $100 \%$ of goat livestock production, and a $7.3 \%$ of the surveyed population depends in a $90 \%$ on the activity, indicating that a significant group (20\%) of the producers depend almost exclusively on the activity. The largest group observed (20\%) depends in a $10 \%$ of revenues generated from the goat livestock; however, a partial dependence between 20 and 50\% consists of the main bulk of the sample (Figure 1d). These results indicate that for a considerable part of the population a great proportion of the family income depends on the goat herding activity, which independently of the commercialized products sustain the survival.

The goat production is performed in a traditional way without high technologies involved and mainly with the minimum veterinary assistance, areas that present input opportunities for a university laboratory and technical center to perform technology and knowledge transfer. In order to identify the most susceptible groups to the transference of technical and managerial training we proceeded to consult within the producers their formal educational level and their training in any specific topics for goat production.

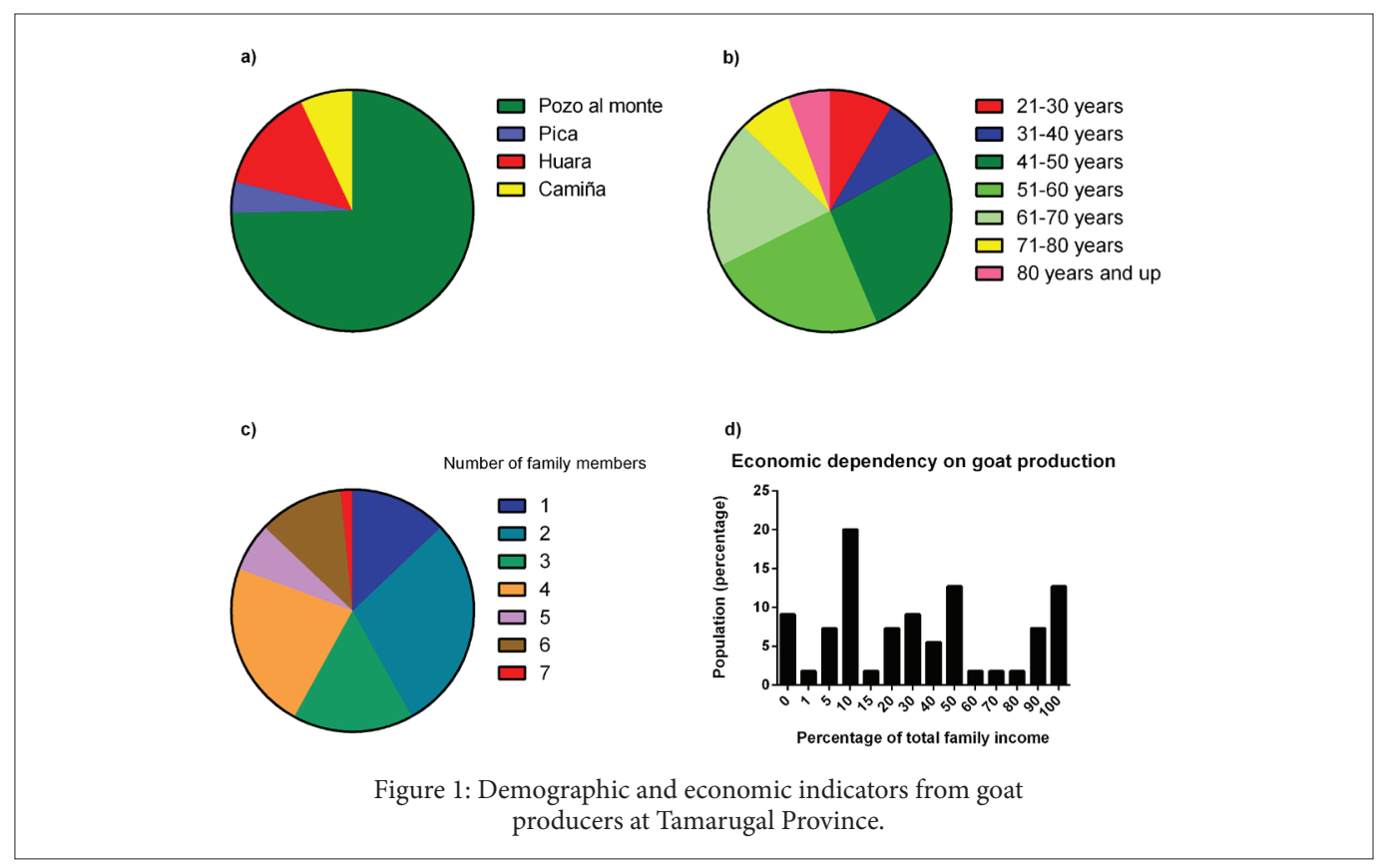

ISSN: 0718-2724. (http://jotmi.org)

Journal of Technology Management \& Innovation @ Universidad Alberto Hurtado, Facultad de Economía y Negocios. 
Most of the consulted herders declared a scholarity level of unfinished elementary school, as an overview, an accumulate of $85.72 \%$ of the consulted population have as maximum reached highschool level completed (Table 1). We observed that the main population of producers that have taken training in goat production belongs to the population with less scholarity level (Table I).

Table 1: Training level of farmers in goat production by scholarity level.

\begin{tabular}{|c|c|c|c|c|c|c|}
\hline & \multicolumn{3}{|c|}{ Received training } & \multicolumn{3}{|c|}{ Percentage per group } \\
\hline & No & Yes & Total & No & Yes & \\
\hline Elementary School (Completed) & & 12 & 3 & 15 & $80,0 \%$ & $20,0 \%$ \\
\hline Elementary School (Unfinished) & & 15 & 7 & 22 & $68,2 \%$ & $31,8 \%$ \\
\hline High School (Completed) & & 14 & 6 & 20 & $70,0 \%$ & $30,0 \%$ \\
\hline High School (Unfinished) & & 5 & 2 & 7 & $71,4 \%$ & $28,6 \%$ \\
\hline Technical School & & 2 & $\mathbf{0}$ & 2 & $100,0 \%$ & $0,0 \%$ \\
\hline Student & & 1 & $\mathbf{0}$ & 1 & $100,0 \%$ & $0,0 \%$ \\
\hline Iliterate & & 1 & $\mathbf{0}$ & 1 & $100,0 \%$ & $0,0 \%$ \\
\hline Universitary education & & 0 & 1 & 1 & $0,0 \%$ & $100,0 \%$ \\
\hline Post-graduated & & 1 & $\mathbf{0}$ & 1 & $100,0 \%$ & $0,0 \%$ \\
\hline Total & & 51 & 19 & 70 & $72,9 \%$ & $27,1 \%$ \\
\hline
\end{tabular}

When asked if ever been trained in goat livestock handling, only $20.8 \%$ of farmers answered positively. Regarding project management, just $6.9 \%$ of the surveyed farmers answered positively. And just $8.3 \%$ of herders declared having receive commercial or business management training (Figure 2). This result reflects the nature of the production in rural areas based on the craftsmanship and tra- dition passed from generation to generation. It is observed that despite the low levels of training received, the most important area that producers have been trained is related to topics in livestock handling, since they reported that in sanitary matters are considered the most urgent area to be covered in order to improve and sustain their production.

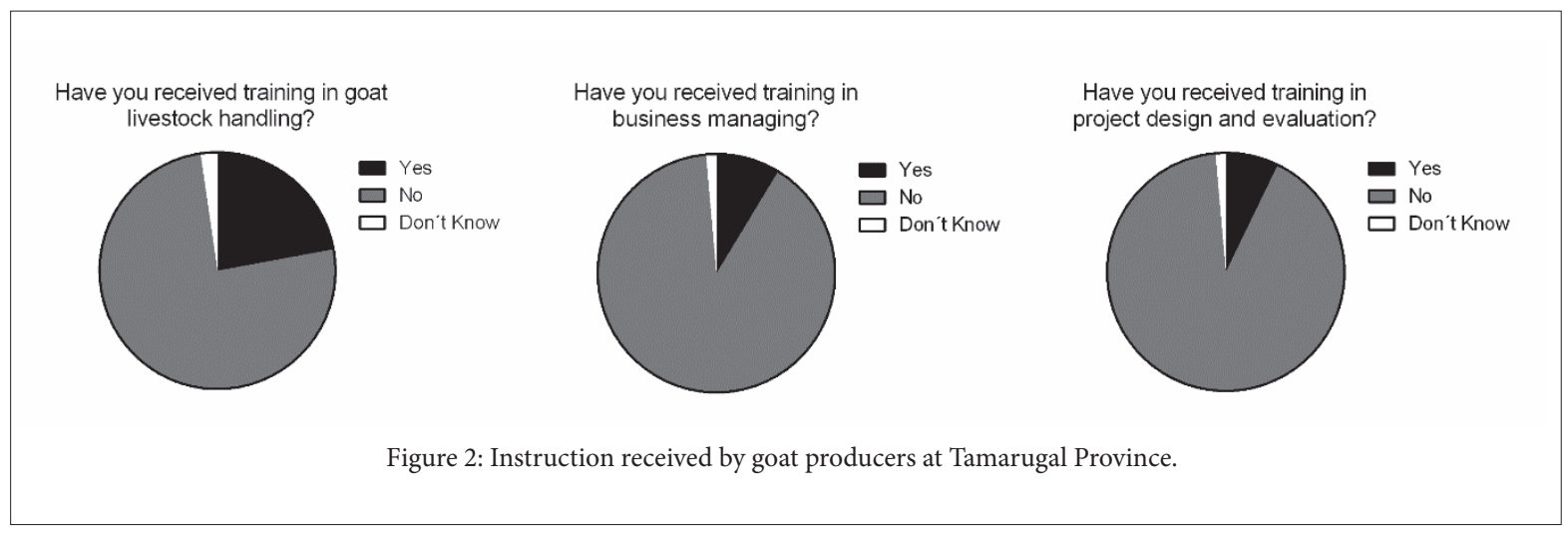

The quantification of the local production indicated that in 2014 the surveyed producers handled 3,250 goats, this being a representation of $94 \%$ of livestock in the area according to the last performed agricultural and livestock census (INE, 2007a, 2007b). Over $88 \%$ of the goat livestock belongs to producers situated in Pozo Almonte, establishing itself as the leading producer town in the province (Table 2).
Regarding livestock reproductive age, $92 \%$ consists of adult female specimens, this being the dominant sex for reproductive functions and milk production. Regarding the number of offspring, this represents $25 \%$ of the total surveyed, evenly distributed between males and females (48\% male and 52\% female). Indicating a weak effective goat population employed for meat commercial purposes. 
Table 2. Goat livestock distribution in Tamarugal province. Locations categorized by sex and reproductive maturity.

\begin{tabular}{|c|c|c|c|c|}
\hline \multirow{2}{*}{ Location } & \multicolumn{2}{|c|}{ Males } & \multicolumn{2}{c|}{ Females } \\
\cline { 2 - 5 } & Adult & Kid & Adult & Kid \\
\hline Pozo al monte & 156 & 357 & 1991 & 361 \\
\hline Pica & 14 & 12 & 112 & 23 \\
\hline Huara & 14 & 15 & 38 & 4 \\
\hline Camiña & 7 & 3 & 2259 & 413 \\
\hline Subtotal & 191 & 387 & 3250 \\
\hline Total & \multicolumn{2}{|c|}{} \\
\hline
\end{tabular}

Performed activities related to health management in goat production were also evaluated. To this were included in the survey the regularly exercised, curative treatment of livestock and animal sanitary bath (Table 3). Regarding preventive health maneuvers, $52 \%$ of herders mostly perform one type of treatment, half of them done with a periodicity of just once a year and the other half performs it twice a year (Table 3). Regarding to curative actions $36 \%$ of producers reported taking them, which when performed are done once a year. Finally, regarding the application of sanitary baths, only $40 \%$ of producers said conducting this type of sanitary practices with poorly controlled frequency (Table 3). These results leave out the deficiencies of best practices aimed for an appropriate health control goat producers of the Province of Tamarugal. The actions oriented towards better health control of livestock are a prerequisite for the development of the industry around the goat derivate products. In the same way, the development of disease diagnostic services specifically focused on goats veterinary treatments allow proper development with the claims of promoting this activity as a center of regional economic development, implying an important field of action for knowledge transfer from the University to the community of goat producers.

Table 3. Periodicity of health management actions taken by goat producers in Tamarugal province.

\begin{tabular}{lcc|ccc} 
Type of control & Number of measures taken & \multicolumn{3}{c}{ Periodicity } \\
\hline Preventive sanitary handling & 1 & 2 & Once a year & Twice a year & Higher \\
\hline Curative treatments & 32 & 6 & 13 & 13 & 1 \\
\hline Sanitary baths & 10 & 16 & 5 & 1 & 9 \\
\hline
\end{tabular}

Considering that an important issue to take in account belongs to the equipment involved in activities related to hording, such as fodder gathering machinery and facilities for distribute and handle the livestock, we surveyed the essential technical equipment necessary sustain the production (Figure 3). The livestock is handled by the $72.7 \%$ herders in some kind of sheltered facilities and $27.3 \%$ without any shelter at all. Corrales where possessed by $97 \%$ of the consulted population. Regarding agricultural machinery, 70 farmers answered this item, of which $38.6 \%$ possess some kind of machinery that allows them to sow and harvest some kind of grain for fodder purposes, been the most common machinery utilized the two-wheel tractor declared by 20 producers. Taking in account that the lands where the herders handle their livestock are located in distant places with difficult access in which the need for a motorized vehicle is considerably helpful, just $53.7 \%$ of the surveyed herders have any kind of personal mobilization, having a not depreciable $46.3 \%$ of producers who move from their houses to the location of their goats by walking.

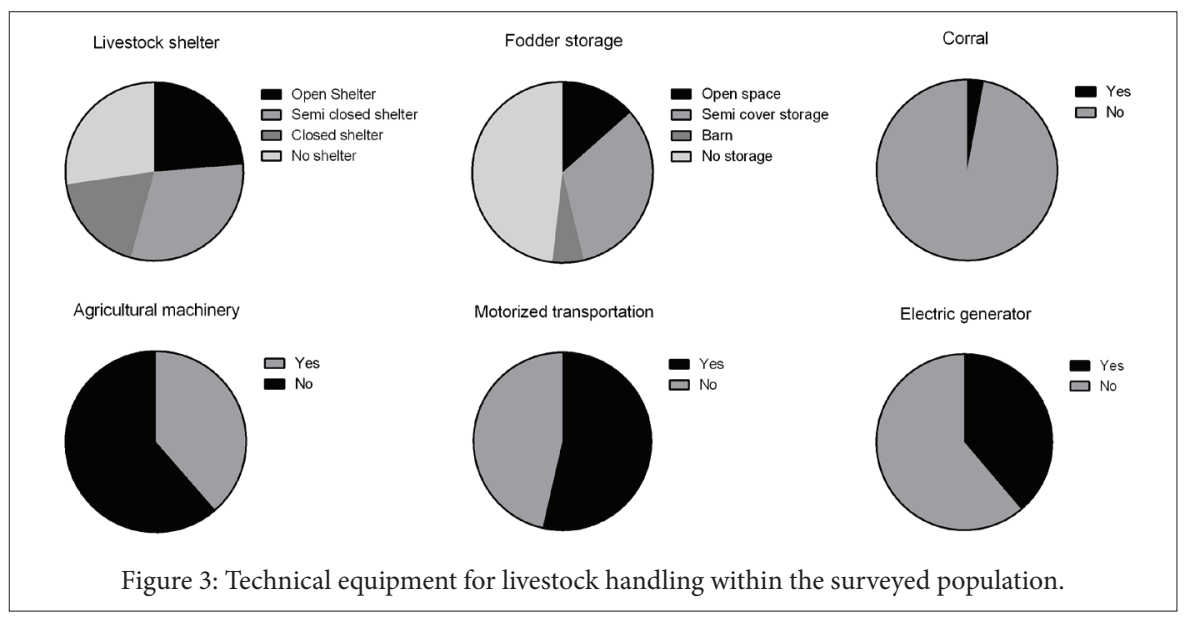

ISSN: 0718-2724. (http://jotmi.org) 
As well the inclusion of independent electric generator corresponds to a very important equipment to have due to the same isolation, for this item just the $38.8 \%$ of the consulted population declared to have it. From these data we can discern that the main population of goat producers at Tamarugal have minimal equipment to keep their cattle, however the respondent universe still shows basic needs that can be managed in a better way with external input, exposing interesting improvement gaps that can be filled by the boost offered by different technical innovation projects that can be carried by individual producers or by association of them.

Referring to commercialization goat derivate products live animal, meat, milk, cheese, leather, hair, and manure, we observed that the main product for these herders is meat (61.4\%) commercialized as live animal in $16.9 \%$ of the cases. Manure is the second most commercialized good, which was declared by the $16.7 \%$ of the producers. On the other hand dairy products, leather and hair did not exceed $5 \%$ of the commercial activity of all producers. Additionally it was found that for important products are discarded. Leather is discarded by $71.2 \%$ of the producers, stored by $15.2 \%$ of them and commercialized without processing by $13.6 \%$ of the consulted herders. Hair is disposed by $89.8 \%$ of the population, stored by $6.8 \%$ and commercialized unprocessed by $1.7 \%$ and processed by $1.7 \%$ (Figure 5 ). Manure is discarded as trash completely by producers who don't sell it.

An important finding was that $11.7 \%$ of the surveyed farmers possess necessary equipment for refrigeration of milk derived products, indicating a need to implement an effective cold chain in order to capitalize real marketing goods obtained from goat livestock. These measures are a must, taking in account that one of the most demanded byproducts with added value from biomass corresponds goat cheese (FAO, 2014; Ribeiro \& Ribeiro, 2010). For this we investigated in the minimum technological capabilities for production and storage of this, which yielded similar results to the capabilities that were determined for milk production. We found that only $13.6 \%$ have necessary equipment for cold storage in refrigerators and only $2.3 \%$ cold chambers for milk and milk derived products, this values are slightly higher than the $10 \%$ of producers who make and sell cheeses.
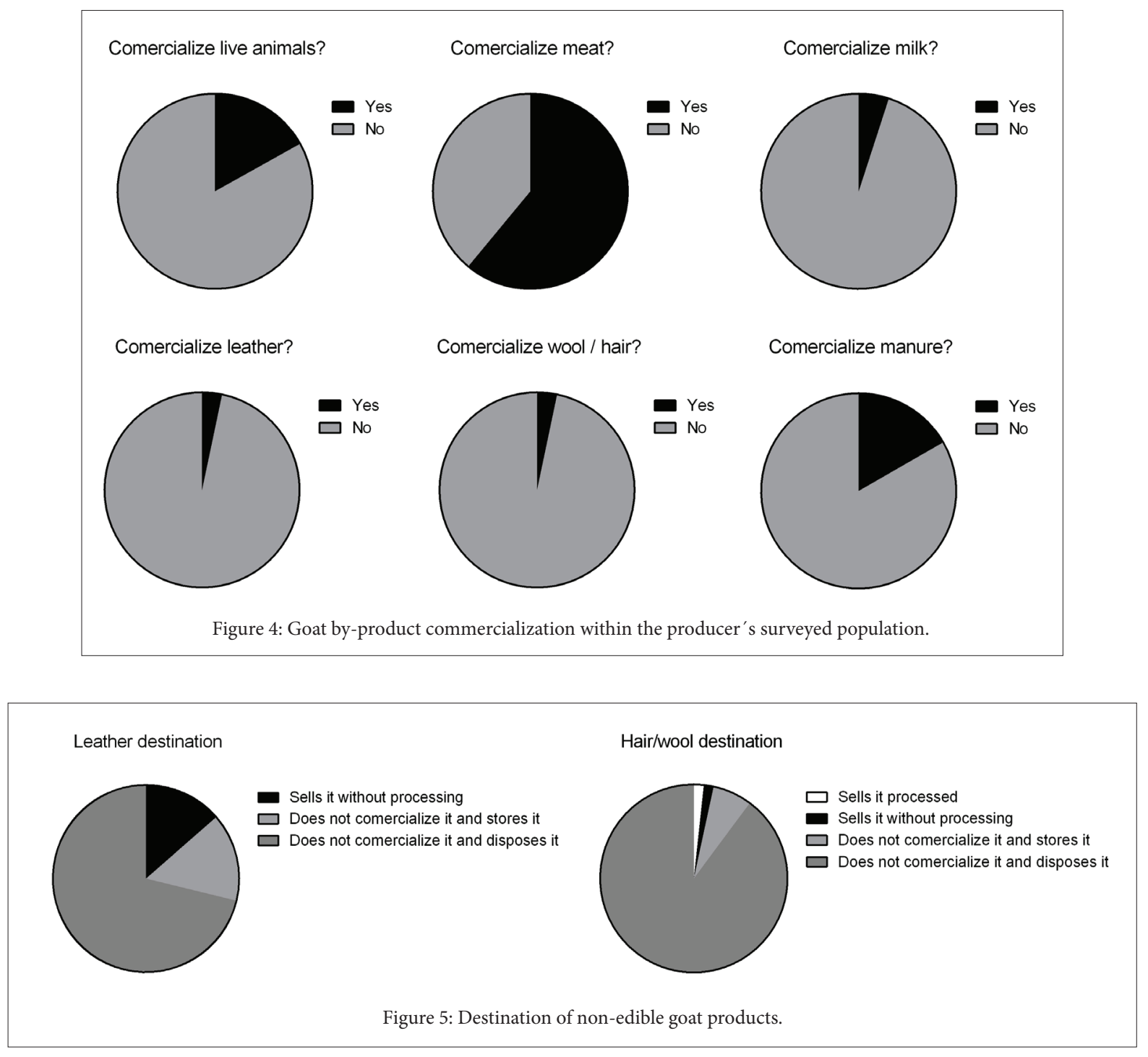

ISSN: 0718-2724. (http://jotmi.org)

Journal of Technology Management \& Innovation @ Universidad Alberto Hurtado, Facultad de Economía y Negocios. 


\section{Discussion}

Under the perspective of the goat local industry nature we can observed that the productive population is a group mainly consisting of elderly adults, having an average education level of high school. They conduct the hording activities in a traditional way, for family sustainability, thus primarily maintained their livestock for their own consumption and for sale in limited quantities used mainly leased and inherited lands. Given that the contribution of this trade is significant for many farmers, a characterization of the state of training, implementation, production and marketing of goat products was performed. In terms of training unpreparedness is denoted toward project management, neglecting important issues in goat production such as the commercial management of goat derived products. This indicates that there is an urgent need to provide tools in these matters to ensure sustainability of producers, taking in account that new generations are forced to move to industrialized cities in order to survive. This lack of training in livestock management is suggested the culprit of the difficulties of the industry to emerge more in the area, a weakness that can be reinforced by the action of transferring knowledge at different levels of production and post-production. Nevertheless externalities such as the lack of established slaughterhouses (Figueroa et al., 2013) and a poor support in the cold chain to ensure the minimum sanitary levels for national and international commercialization are actions to be taken by entities that determine public policies in the agricultural and livestock sector in this region of the country.

Moreover in terms of basic technological equipment the presence of minimal elements necessary part of the survey population was observed, however, in terms of producing products of great importance (for human consumption) substantive flaw was evident regarding the minimum necessary equipment, so in addition to complementary assets such as those evidenced in the market study (absence of standardized supply chain and sanitary standards) highlight a marked weakness in terms of these products (milk, cheese, meat) for which it would be necessary not only centered advise producers of the area, but to establish a link with effective and prompt authorities to generate a backup in the value chain for food products, especially for products that generate significant added value (Haenlein, 1996, 2007) as in the case of gourmet products, which allow larger increase for producers and for the region, not only nationally but internationally (Boyazoglu \& Morand-Fehr, 2001). An important opportunity to consider involves billing goat milk derivatives for the cosmetic industry and its use for treating allergies due to its hypoallergenic properties (Haenlein, 2007; Park, 1993; Scintu \& Piredda, 2007).

The observed results regarding the commercialized items and also the disposed by-products, allowed us to identify a major opportunity in the use of discarded leather and hair. This indicates an important need for training and search for links to generate important value products from these raw materials is necessary in order to produce income without the need of constraint cold chain processing needs fewer regulations and complementary assets that food products, leather for the production of clothing and shoes (Flohr, 2013; Strasser et al., 2013) and hair for use in textile industry and the generation of alternative assets which can be produced and show profitability even in small farms (Demircan et al., 2011).

Taking into account the optimization of a value chain in which there are cultural and external barriers to counseling complementary assets, it has to be considered that an important commercial potential could be used in the manufactured goods that require less externalities regarding food safety, and point to the use of raw materials currently discarded to avoid the loss of value currently observed. Thus, in order to ensure the sustainability of the local industry should place emphasis on improving production processes and improved technical capabilities, covering such technological gaps with transfer from university to industry taking in account the respective sensitivity of this community to these inputs (Little et al., 2014)2014.

\section{Acknowledgements}

The following research was funded by the Regional Government of Tarapacá, through the Innovation Fund for Competitiveness. BIP30170222-0 "Innovation, development and management program for livestock industrial sector competitiveness at Tamarugal Province". SD designed and wrote the paper; SD, PF and PC designed the methodology of the survey, PC conducted the surveys and PF performed the statistical analysis, VV, JCR, IB and DH made proofreading of the manuscript. All authors read and approved the manuscript

\section{References}

Boyazoglu, J., \& Morand-Fehr, P. (2001). Mediterranean dairy sheep and goat products and their quality: A critical review. Small Ruminant Research, 40(1), 1-11. doi: http://dx.doi.org/10.1016/S09214488(00)00203-0

Cannarella, C., \& Piccioni, V. (2011). Traditiovations: Creating innovation from the past and antique techniques for rural areas. Technovation, 31(12), 689-699. doi: http://dx.doi.org/10.1016/j.technovation.2011.07.005

Demircan, V., Yilmaz, H., Gul, M., \& Koknaroglu, H. (2011). Effect of farm size on performance and profitability of hair goat production in Isparta, Turkey. Animal Production Science, 51(5), 454-459. doi: http://dx.doi.org/10.1071/AN10056

Drejer, A., \& Gudmundsson, A. (2002). Towards multiple product development. Technovation, 22(12), 733-745. doi: http://dx.doi. org/10.1016/S0166-4972(02)00024-X

Dubeuf, J.-P., \& Boyazoglu, J. (2009). An international panorama of goat selection and breeds. Livestock Science, 120(3), 225-231. doi: http://dx.doi.org/10.1016/j.livsci.2008.07.005

FAO. (2014, July 1st 2015). FAOSTAT. Retrieved July 1st 2015, 2015, from http://faostat3.fao.org/download/P/PA/E

Figueroa, P., Cabello, P., Vrsalovic, V., Galvez, D., \& Diez de Medina, S. (2013). Technology Transfer from Academia to Rural Communi- 
ties: The Case of Caprines in vitro Fecundation and Local Livestock Market in Tamarugal Province in Chile. Journal of Technology Management and Innovation, 8(4), 186-194.

Flohr, M. (2013). Leather, leatherwork The Encyclopedia of Ancient History: John Wiley \& Sons, Inc.

Haenlein, G. F. W. (1996). Status and prospects of the dairy goat industry in the United States. J Anim Sci, 74(5), 1173-1181.

Haenlein, G. F. W. (2007). About the evolution of goat and sheep milk production. Small Ruminant Research, 68(1-2), 3-6. doi: http://dx. doi.org/10.1016/j.smallrumres.2006.09.021

INE. (2007a). Síntesis geográfica de la Región de Tarapacá, División Político Administrativa y Censal 2007. In INE (Ed.).

INE. (2007b). VII Censo agropecuario y forestal. In INE (Ed.).

Little, P. D., Debsu, D. N., \& Tiki, W. (2014). How pastoralists perceive and respond to market opportunities: The case of the Horn of Africa. Food Policy, 49, Part 2(0), 389-397. doi: http://dx.doi.org/10.1016/j. foodpol.2014.10.004
Oman, J. S., Waldron, D. F., Griffin, D. B., \& Savell, J. W. (1999). Effect of breed-type and feeding regimen on goat carcass traits. J Anim Sci, 77(12), 3215-3218.

Park, Y. W. (1993). Hypo-allergenic and therapeutic significance of goat milk. Small Ruminant Research, 14(2), 151-159. doi: 10.1016/0921-4488(94)90105-8

Ribeiro, A. C., \& Ribeiro, S. D. A. (2010). Specialty products made from goat milk. Small Ruminant Research, 89(2-3), 225-233. doi: http://dx.doi.org/10.1016/j.smallrumres.2009.12.048

Scintu, M. F., \& Piredda, G. (2007). Typicity and biodiversity of goat and sheep milk products. Small Ruminant Research, 68(1-2), 221231. doi: http://dx.doi.org/10.1016/j.smallrumres.2006.09.005

Strasser, J., Dannenberg, P., \& Kulke, E. (2013). Temporary resource availability and quality constraints in the global leather value chain - The impact of the festival of sacrifice on the leather industry in Bangladesh. Applied Geography, 45(0), 410-419. doi: http://dx.doi. org/10.1016/j.apgeog.2013.02.008 